\title{
Response surface methodology as a statistical tool for optimization of physio-biochemical cellular components of microalgae Chlorella pyrenoidosa for biodiesel production
}

\author{
Kulvinder Bajwa $^{1}$ D $\cdot$ Narsi R. Bishnoi $^{1} \cdot$ Anita Kirrolia $^{1} \cdot$ Saloni Gupta ${ }^{1} \cdot$ Silambarasan Tamil Selvan $^{2}$
}

Received: 18 January 2018 / Accepted: 5 May 2019 / Published online: 28 June 2019

(c) The Author(s) 2019

\begin{abstract}
The current study utilized Box-Behnken design of the response surface methodology, aimed at identifying the best levels of particular variables. An experimental design was performed on Chlorella sp. considering initial nitrogen, phosphorus and iron concentration as independent variables. Lipid, biomass, chlorophyll, carbohydrate and protein contents were analysed as response variables. Various physio-biochemical attributes were studied under varied concentration of nutrients in BG11 media, nitrate $\left(\mathrm{NaNO}_{3}, 10-750 \mathrm{mg} \mathrm{mL}{ }^{-1}\right)$, phosphate $\left(\mathrm{K}_{2} \mathrm{HPO}_{4}, 40-120 \mathrm{mg} \mathrm{mL}^{-1}\right)$, iron (ferric ammonium citrate, 3-9 $\mathrm{mg} \mathrm{mL}^{-1}$ ) with an objective to establish the actual potential of Chlorella pyrenoidosa under phototrophic nutrient stress conditions were obtained lipid percentage $(35.4 \mathrm{dcw} \%)$ and biomass yield $\left(1.89 \mathrm{~g} \mathrm{~L}^{-1}\right)$. A Prob $>F$ value of $<0.05$ and $>0.05$ indicated model terms which were significant and non-significant, respectively. The fit of model yielded $R^{2}$ values up to $96.25 \%$ for lipids and $94.12 \%$ for biomass; similar values were obtained for proteins, carbohydrate and chlorophyll. FAME profile of Chlorella pyrenoidosa contained palmitic (C16:0, stearic acid), (C18:0) oleic (C18:1), linoleic C18:2 and linolenic (C18:3) which showed that Chlorella pyrenoidosa possessed a favourable fatty acids profile that can be successfully utilized for biodiesel production.
\end{abstract}

Keywords Microalgae $\cdot$ Chlorella pyrenoidosa $\cdot$ Lipid $\cdot$ Biomass $\cdot$ RSM $\cdot$ Box-Behnken design (BBD) $\cdot$ Transmethylation $\cdot$ FAME and biodiesel

\section{Introduction}

Biofuels, the sustainable energy system, may be regarded as a cost-effective, trustworthy and environmental-friendly system that efficiently makes use of local resources (Shahare et al. 2017). Biodiesel comprises fatty acid alkyl esters of long-chain fatty acids with short-chain alcohols, primarily methanol and ethanol, and is generally produced from the trans-esterification of triglycerides by alkali acids or enzymes in vegetable oils or animal fats (Ma and Hanna 1999; Zhang et al. 2003; Noureddini et al. 2005; Wang et al.

Kulvinder Bajwa

kulvinderbajwa3@gmail.com

1 Department of Environmental Science and Engineering, Guru Jambheshwar University of Science and Technology, Hisar, Haryana 125001, India

2 Department of Microbiology, School of Biosciences, Periyar University, Salem, Tamil Nadu 636011, India
2007; Fadhil et al. 2016). Microalgal cultivation is environmentally friendly because the microalgal biomass can be utilized for the productions of biofuels, food and feed supplements, pharmaceuticals, nutraceuticals and cosmetics (Show et al. 2017). Microalgal biodiesel appeared to be the most promising renewable biofuel that has the potential to entirely substitute petroleum-derived transport fuel (Chisti 2008; Harun et al. 2010; Bajwa and Bishnoi 2016). Some advantages such as easily cultivable, devoid of any seasonal changes, high lipid production capability, superior photosynthetic efficiency, no competition with food crops for land and water, nutrients uptake from wastewater, ability to produce substantial amount of triacylglycerides (TAG) and shorter doubling time make them better than other available feedstocks (Kiran et al. 2014; Sharma et al. 2012; Wang et al. 2010; Chisti 2008; Bajwa and Bishnoi 2016; Sharma et al. 2015). Among the numerous algal species, Chlorella pyrenoidosa is identified as a potential strain for fuel production because of its rapid growth and enormous amount of lipid content (Chelladurai and Perumalsamy 2017). Mixotrophic 
and heterotrophic cultivation has been suggested as feasible alternative for higher biomass yield and lipid productivity, which is a key step in the reduction in biodiesel cost ( $\mathrm{Yu}$ et al. 2009; Cheirsilp and Torpee 2012; Ren et al. 2013). Several factors influencing algal growth both qualitatively and quantitatively include light, temperature, media composition, nitrogen and phosphate source, carbon sources, nutrient limitation, aeration, photoperiod (dark/light) condition, oxygen, $\mathrm{CO}_{2}, \mathrm{pH}$, salinity, heterotrophic cultivation and toxic chemicals as abiotic factors (Mata et al. 2010; Singh and Singh 2015). Nutrient availability has a substantial impact on growth and culturing of microalgae and broad effects on their lipid content and fatty acid composition (El-Kassas 2013). So far, various studies have been carried out to demonstrate that the nitrogen source was the important nutrition in the medium affecting the growth and lipid accumulation (Li et al. 2008). Previous studies have demonstrated that lipid content in some microalgae increases under nitrogen-deprived condition (Illman et al. 2000; Hsieh and Wu 2009). Similarly, phosphorus and nitrogen are essential nutrients for metabolic growth of microalgae (Sharma et al. 2015). Studies have shown that the phosphorus-deprived conditions are responsible for significant lipid accumulation in Chlorella sp. Chaetoceros sp. High lipid accumulation was reported under nitrogen-deprived conditions in microalgal species, viz. Neochloris oleoabundans, Nannochloris sp., Chlorella muelleri and Scenedesmus sp. (Courchesne et al. 2009; Radakovits et al. 2010; Gao et al. 2013; Blinová et al. 2015).

RSM is a novel arithmetical design employed to evaluate problems which in the response is dependent on several independent variables with an objective to maximize the process variables for achieving optimum response (Box and Behnken 1960). The main objective of RSM is determination of the optimized operational condition of the process or to determine a region that satisfies the operating specifications (Myers and Montgomery 2002). RSM uses quantitative data from appropriate experiments to determine and simultaneously solve multivariate equations (Tokcaer et al. 2006; Silambarasan et al. 2017). RSM reduces the number of experiments eventually saving chemicals, time and labour. Furthermore, it offers a rapid and unfailing prediction of response, making it a beneficial option for experimental design. The Box-Behnken design was taken as it fulfilled most of the requirements for interaction study for various factors (Molina Grima et al. 1999; Su et al. 2009). Trans-esterification process is a very important step for biodiesel production at industrial scale. Homogeneous alkali catalysts like potassium hydroxide or sodium hydroxide are utilized by the common industrial practices (Mata et al. 2010; Yu et al. 2015). Physico-chemical properties of biodiesel are assessed by fatty acids profile such as saturated, monounsaturated and polyunsaturated fatty acid (Kumar and Chauhan 2013). The biodiesel parameters, viz. cetane number, iodine value and oxidation stability, were correlated with degree of unsaturated fatty acids, whereas the cold filter plugging was correlated with long-chain saturated fatty acids (Chuah et al. 2016). Gas chromatography (GC) is the most popular method to characterize fatty acid profiles of lipids in biological materials. In fatty acid profile analysis, lipids need to be converted into fatty acid methyl esters (FAME) in order to improve their volatility and hence ensure better GC peak shape (Masurkar and Vakil 2015). The FAME elute at different retention times, due to their different degrees of interaction. FAME can be determined by comparing their retention time provided in the literature (Quehenberger et al. 2011; Renita and Joshua 2011). Thus, the aim of the present study is to evaluate simultaneously the effect of nitrogen, phosphorus and iron in BG-11 medium on growth and other physio-biochemical attributes of Chlorella pyrenoidosa by using Box-Behnken model and fatty acids detection by using GCMS.

\section{Materials and methods}

\section{Isolation and molecular characterization}

The freshwater microalgal species was isolated from the freshwater pond at Shahidawaali village, Dist. Sirsa (Haryana), India. Genomic DNA from microalgal sample was extracted by using cetyl trimethyl ammonium bromide (CTAB) method (Rogers and Bendich 1994). Polymerase chain reaction (PCR) was analysed to amplify $18 \mathrm{~S}$ rRNA gene of microalgae using forward (5"GGGACCCGTTACCGTAGGTGAACCTGC-3") and reverse primers (5"-GGGATCCATATGCTTACGTTC CGCGGAT-3"). The purified PCR products were sequenced by Amnion Biosciences Pvt. Ltd. (Bengaluru, India). Comparisons of nucleotide sequences and statistical significance of matches were carried out with the National Centre for Biotechnology Information (NCBI) nucleotide BLAST program.

\section{Analytical methods for physio-biochemical parameters}

\section{Extraction of lipid}

The extraction of total lipid was carried out by mixing methanol-chloroform $(2: 1.5 \mathrm{v} / \mathrm{v})$ with the algal samples using slightly modified version of Bligh and Dyer's method (Bligh and Dyer 1959). According to Suganya and Renganathan (2012), the oil extraction yield (\%w/w) was determined by the following formula:

Oil extraction yield $(\mathrm{dcw} \%)=\frac{\text { Weight of extracted oil }}{\text { Weight of biomass }} \times 100$ 


\section{Estimation of dry Biomass}

Dry cell biomass was measured as the cell density (dcw) at OD625 of an 11-day-old culture at dilutions ranging from 0.2 to 1.0. The dry biomass was calculated using the regression equation as the linear relationship given by Yount (2006)

$y=0.137 x+0.1766, \quad R^{2}=0.9859$

\section{Extraction and determination of photosynthetic pigment}

Chlorophyll content of the algae was estimated spectrophotometrically at 650 and $665 \mathrm{~nm}$, MacKinney (1941). The concentration of chlorophyll was calculated using the formula:

Total chlorophyll $\left(\mathrm{mgmL}^{-1}\right)=2.55 \times 10^{-2} E 650$

$$
+0.4 \times 10^{-2} E 665 \times 10^{3}
$$

\section{Extraction and determination of total soluble carbohydrate by Anthrone reagent}

Glucose was determined at $625 \mathrm{~nm}$ using Anthrone reagent method by Dubois et al. (1956). The sugar content was calibrated against standard curve prepared by using graded conc. of glucose dilution ranging from 0.2 to 1 and expressed in terms of $\mathrm{mg} \mathrm{mL}^{-1} y=0.636 x+0.0592, R^{2}=0.9595$ where $y$ is the concentration of glucose and $x$ the optical density.

\section{Estimation of total protein}

The protein content was estimated using Lowry's method. Protein concentration was calculated from the standard curve prepared with bovine serum albumin (BSA) (Lowry et al. 1951):

$y=0.1097 x-0.0005, \quad R^{2}=0.9989$

\section{Optimization of nitrogen, phosphorus and iron concentrations in BG-11 media using Box-Behnken model}

The statistical experiments were carried out using Design Expert 7.0.0 Box-Behnken model (Miao et al. 2006). The experimental design consisted of three nutrient stress factors: sodium nitrate concentration (nitrogen source), dipotassium phosphate concentration (phosphorous source) and ferric ammonium citrate concentration (iron source) (Table 1). Seventeen experiments were designed by Design Expert 7.0.0 Box-Behnken model and conducted at $25^{\circ} \mathrm{C}$ as per experimental setup. The relationship between independent variables and responses was evaluated by using secondorder polynomial equation. The adequacy of designed model was evaluated by coefficient of determination regression $\left(R^{2}\right)$
Table 1 Levels of three independent variables used in RSM in terms of actual and coded factors of Box-Behnken design

\begin{tabular}{llll}
\hline Process variable $\left(\mathrm{mg} \mathrm{L}^{-1}\right)$ & Low $(-1)$ & Medium $(0)$ & High $(+1)$ \\
\hline $\mathrm{NaNO}_{3}$ & 10 & 388 & 750 \\
$\mathrm{~K}_{2} \mathrm{HPO}_{4}$ & 20 & 40 & 60 \\
Ferric ammonium citrate & 30 & 60 & 90 \\
\hline
\end{tabular}

and model $P$ value. The analysis of variance (ANOVA) of various responses was obtained after applying independent variables for lipid productivity (dcw\%), biomass $\left(\mathrm{g} \mathrm{L}^{-1}\right)$, total chlorophyll $\left(\mu \mathrm{g} \mathrm{mL}^{-1}\right)$, carbohydrate $\left(\mathrm{mg} \mathrm{ml}^{-1}\right)$, protein ( $\mathrm{mg} \mathrm{mL}^{-1}$ ) by using response surface methodology.

ANOVA analysis of predicted model was carried out to estimate its statistical significance. The quality of the fit polynomial model was expressed by the coefficient of determination regression $\left(r^{2}\right)$, and its statistical significance was tested by the Fisher F-test. Model terms were accepted or rejected based on the $p$ value (probability) with a $95 \%$ of confidence level. BBD responses were fitted by a secondorder polynomial in order to correlate response with independent factors. The polynomial equation is in the following form: $Y=\beta_{0}+\Sigma \beta_{i} X_{i}+\Sigma \beta_{i} X_{i} X_{j}+\Sigma \beta_{i i} X_{i 2} \ldots \Sigma \beta_{i i} X_{n}$ where $X_{1}, X_{2}$ and $X_{3}$ represent the coded levels of the independent variables as described in Table 1 and $\beta_{0}, \beta_{i}$ and $\beta_{j}(i, j=1,2,3$, 4) are the coefficient estimates, where $\beta_{0}$ is the interception term, $\beta_{i}$ is the linear term, $\beta_{i i}$ is the quadric term and $\beta_{i i}$ is the interaction term. The overall second-order polynomial mathematical relationship of response $Y$ and the three variables, i.e. $\mathrm{NaNO}_{3}, \mathrm{~K}_{2} \mathrm{HPO}_{4}$ and ferric ammonium citrate, can be approximated by quadratic equation.

\section{Extraction of diesel hydrocarbons and analysis of biodiesel using gas chromatography mass spectroscopy (GCMS)}

\section{Direct trans-methylation method}

The lipid samples were methylated by heating under reflux using methanolic $\mathrm{HCl}(5 \%)$ at $60{ }^{\circ} \mathrm{C}$ as shown in Fig. 1a. Extraction of hydrocarbon was carried out by using petroleum ether $60{ }^{\circ} \mathrm{C}$ in hot water bath. The ether extract was washed three times with deionized water then dried over anhydrous sodium sulphate, filtered off and collected sample (Abdo et al. 2014) and subjected to GCMS analysis.

The analysis of FAME produced from microalgal oil was performed on gas chromatograph mass spectrometer (PerkinElmer Clarus-580) equipped flame ionization detector with two narrow bore capillary columns Agilent, DB-225, ( $30 \mathrm{~m} \times 250 \mu \mathrm{m}$, film thickness $0.25 \mu \mathrm{m}$ ). The pressure of the carrier gas (helium) was 6.08 Psi at the primary oven temperature with flow rate $67 \mathrm{~mL} \mathrm{~min}{ }^{-1}$. The temperature of the 
Fig. 1 Extraction of hydrocarbons. a Heating under reflux method and $\mathbf{b}$ microscopic image of Chlorella pyrenoidosa $(\times 100 \mathrm{X})$
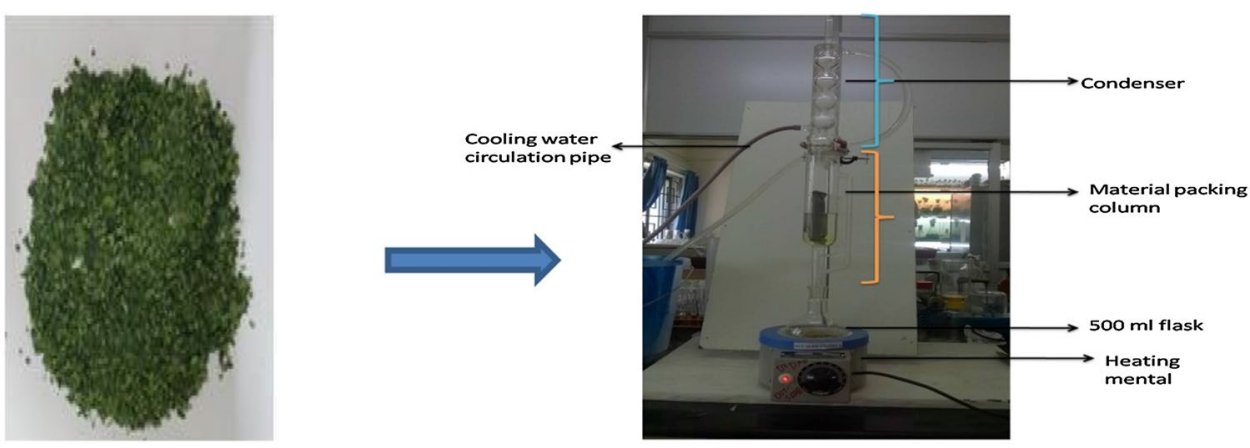

Algal Biomass

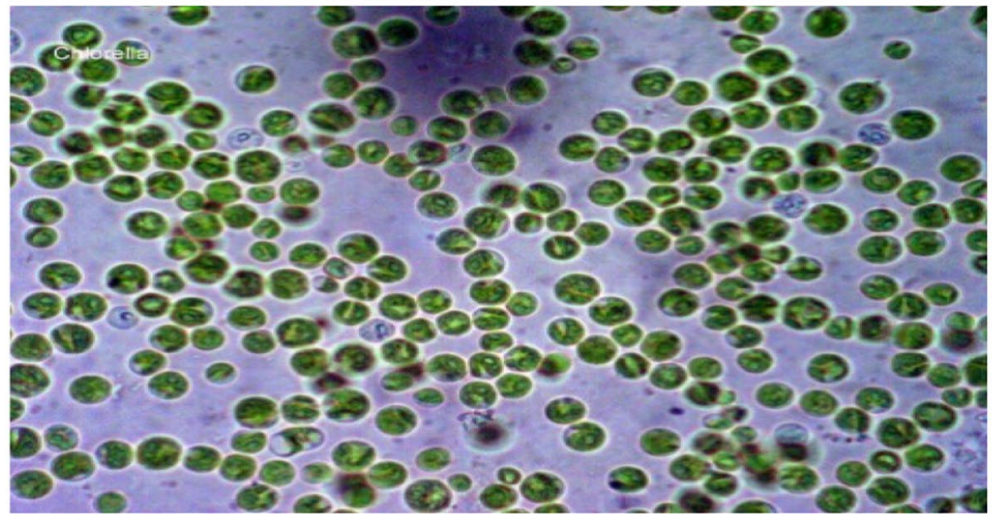

transfer line and of the ion source was set to a value of 320 and $280{ }^{\circ} \mathrm{C}$, respectively. The $1.0 \mu \mathrm{L}$ volume of sample was injected in column. Peak identification of algal oil was performed, and an oil compound was identified with retention times. The mass spectra obtained are compared with Wiley and NIST libraries (Wiley Registry TM, 8th Edition Mass Spectral Library and the NIST 08 Mass Spectral Library (NIST/EPA/NIH) 2008 version) with an acceptance criterion of a match above a critical factor of $80 \%$ (Guan et al. 2011).

\section{Results and discussion}

\section{Partial sequencing of microalgae}

The freshwater microalgal species was isolated from the freshwater pond and preliminarily identified as Chlorella sp. on the basis morphological features and habitat (Fig. 1b). The 18S rRNA partial sequence of a gene amplified from the strain Chlorella sp. was 610 bp. The molecular phylogenetic tree analysis indicated that this strain had a close relationship with Chlorella pyrenoidosa and confirmed as Chlorella pyrenoidosa (Fig. 2b). The partial gene sequence of 18S rRNA of Chlorella pyrenoidosa was deposited to NCBI GenBank under accession no. KU236002.1.

\section{Optimization of nitrogen, phosphorus and iron concentrations in BG-11 media using Box-Behnken model}

The Box-Behnken design (BBD) (Design Expert 7.0.0 trial version; Stat-Ease, Minneapolis, $\mathrm{MN}$ ) of five variables and three levels, each with three concentric point combinations were used to identify the optimum variable level for the indigenous isolate of Chlorella pyrenoidosa. The minimum, central and maximum levels for each design variable used in the Box-Behnken for various responses was listed in Table 2. The experimental design was applied for each variable maximum and minimum level for each design variable. The independent factors that exhibited higher influence on the response variables were listed hierarchically in Table 3. Analysis of variance was used in order to ensure a good model as explained in Table 4. A Prob $>F$ value of $<0.05$ and $>0.05$ indicated model terms which were significant and non-significant, respectively. The fit of model yielded $R^{2}$ values up to $96.25 \%$ for lipid and $94.12 \%$ for biomass; similar values were obtained for proteins, carbohydrate and chlorophyll (Table 4 ). The predicted $R^{2}$ and adjusted $R^{2}$ values closer to 1.0 were in a reasonable agreement indicating the better fitness of model to obtain experimental data. Adequate precision determined the signal-to-noise ratio, and numerical values greater than 4 indicated that model can be used to navigate the designed space. A very small 
Fig. 2 Phylogenetic tree analysis based on 18s rRNA sequencing of Chlorella pyrenoidosa showing relationship with other universal identified species

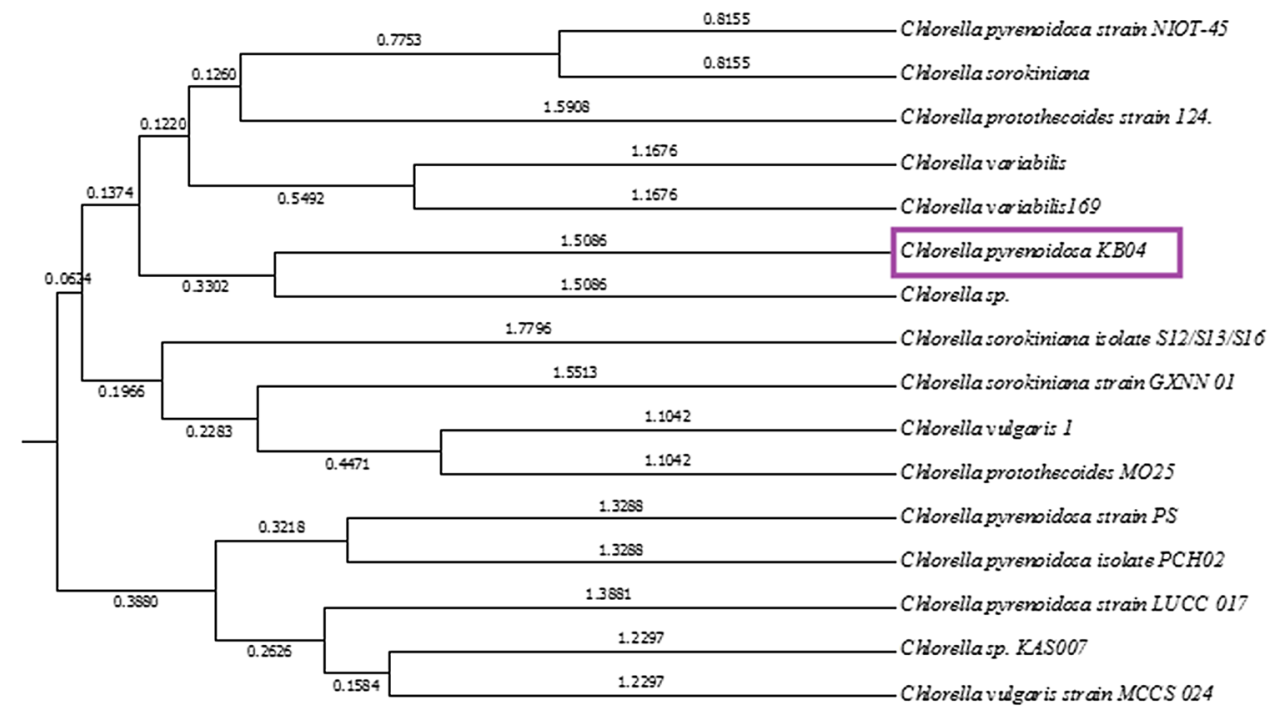

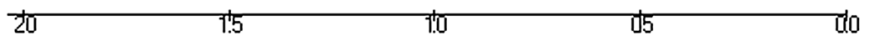

Table 2 The various variable levels used in the Box-Behnken design for Chlorella pyrenoidosa

\begin{tabular}{|c|c|c|c|c|c|c|c|c|}
\hline Std. & $\begin{array}{l}\text { Sodium } \\
\text { nitrate } \\
\left(\mathrm{mg} \mathrm{L}^{-1}\right)\end{array}$ & $\begin{array}{l}\text { Di-potassium } \\
\text { hydrogen phosphate } \\
\left(\mathrm{mg} \mathrm{L}^{-1}\right)\end{array}$ & $\begin{array}{l}\text { Ferric ammonium } \\
\text { citrate }\left(\mathrm{mg} \mathrm{L}^{-1}\right)\end{array}$ & $\begin{array}{l}\text { Lipid } \\
\text { yield } \\
\text { (dcw\%) }\end{array}$ & Biomass $\left(\mathrm{g} \mathrm{L}^{-1}\right)$ & $\begin{array}{l}\text { Total } \\
\text { chlorophyll } \\
\left(\mu \mathrm{g} \mathrm{mL}{ }^{-1}\right)\end{array}$ & $\begin{array}{l}\text { Carbo- } \\
\text { hydrate } \\
\left(\mathrm{mg} \mathrm{L}^{-1}\right)\end{array}$ & Protein $\left(\mathrm{mg} \mathrm{L}^{-1}\right)$ \\
\hline 1 & 380 & 40 & 6 & 35.4 & 1.89 & 20.16 & 0.354 & 0.0342 \\
\hline 2 & 750 & 40 & 9 & 26.159 & 1.68 & 12.8 & 0.265 & 0.024 \\
\hline 3 & 10 & 60 & 6 & 23.118 & 1.17 & 8.929 & 0.231 & 0.023 \\
\hline 4 & 380 & 20 & 3 & 24.278 & 1.07 & 13.47 & 0.247 & 0.028 \\
\hline 5 & 380 & 20 & 9 & 30.35 & 1.11 & 16.438 & 0.305 & 0.0305 \\
\hline 6 & 380 & 40 & 6 & 35.4 & 1.89 & 20.16 & 0.354 & 0.0345 \\
\hline 7 & 750 & 60 & 6 & 22.98 & 1.44 & 10.96 & 0.229 & 0.0229 \\
\hline 8 & 10 & 40 & 3 & 17.279 & 1.36 & 13 & 0.177 & 0.018 \\
\hline 9 & 380 & 40 & 6 & 35.41 & 1.89 & 20.16 & 0.354 & 0.034 \\
\hline 10 & 750 & 40 & 3 & 18.251 & 1.8 & 15.1 & 0.185 & 0.0185 \\
\hline 11 & 380 & 60 & 9 & 27.968 & 1.8 & 11.478 & 0.278 & 0.0276 \\
\hline 12 & 10 & 40 & 9 & 24.193 & 1.54 & 12 & 0.249 & 0.0249 \\
\hline 13 & 380 & 60 & 3 & 19.218 & 1.4 & 17.879 & 0.198 & 0.0198 \\
\hline 14 & 380 & 40 & 6 & 35.4 & 1.89 & 20.16 & 0.354 & 0.0348 \\
\hline 15 & 380 & 40 & 6 & 35.4 & 1.89 & 20.16 & 0.354 & 0.0356 \\
\hline 16 & 10 & 20 & 6 & 25.218 & 1.31 & 9.2 & 0.258 & 0.028 \\
\hline 17 & 750 & 20 & 6 & 28.308 & 1.42 & 10.539 & 0.28 & 0.028 \\
\hline
\end{tabular}

All the experiments were run at central value

value of coefficient variation in lipid, biomass, chlorophyll, carbohydrate and protein $(0.016 \%, 10.42 \%, 0.77 \%, 0.71 \%$, $2.16 \%)$ and low standard deviation value $(4.29,0.16,0.77$, $1.96,5.92)$, respectively, clearly indicated very high degree of precision and good reliability of the experimental data.

The second-order polynomial equation was used to evaluate the relationship between various variables and responses. The regression equation coefficients were calculated, and data fitted to a second-order polynomial equation. A flat surface of three-dimensional response graphs indicated an optimum condition for responses such as lipid accumulation, biomass production, carbohydrate consumption and chlorophyll and protein contents were shown in Fig. 4a-e. The experimental details were provided by Design Expert from the analysis of all the data points of normal probability, and the studentized residual was approximately linear and found 
Table 3 Independent factors influence on the response variables

\begin{tabular}{ll}
\hline Response variables & $\begin{array}{l}\text { Equation terms (descendant } \\
\text { order of influence) }\end{array}$ \\
\hline Lipids & $A, B, C, A B, A C, B C, A^{2}, B^{2}, C^{2}$ \\
Biomass & $A B, A C, B C, A^{2}, B^{2}, C^{2}$ \\
Chlorophyll & $A, C, A B, A C, B C, A^{2}, B^{2}, C^{2}$ \\
Carbohydrates & $A, B, C, A B, B C, A^{2}, B^{2}, C^{2}$ \\
Protein & $A B, A C, B C, A^{2}, B^{2}, C^{2}$
\end{tabular}

Factors: $A-\mathrm{NaNO}_{3}, B-\mathrm{K}_{2} \mathrm{HPO}_{4}, C$-ferric ammonium citrate

to be lie around zero line, indicating the suitability of model and showing that the variance was associated with prediction changes over the design space as shown in Fig. 5a-e that clearly indicated the adequacy of model and have adequated harmony with predicted and actual data obtained by applying BBD.

The lipid yield, three linear $(A, B, C)$, interactive $(A B, A C$, $B C)$ and quardratic $\left(A^{2}, B^{2}, C^{2}\right)$ model terms were found to be significant. The chlorophyll contents, two linear $(A, C)$, interactive $(A B, A C, B C)$ and quardratic $\left(A^{2}, B^{2}, C^{2}\right)$ model terms were significant, whereas for carbohydrate content three linear $(A, B, C)$, interactive $(A B, B C)$ and quardratic $\left(A^{2}, B^{2}, C^{2}\right)$ model terms were significant. In case of biomass yield, quardratic $B^{2}$ term was significant. The protein content, two linear $(B, C)$ interactive $B C$ and quardratic $A^{2}, B^{2}$, $C^{2}$ model terms were significant. All of the significant terms were found to contribute more towards the responses than non-significant terms. The multiple correlation coefficient $R^{2}$ value for all responses suggested that the quadratic polynomial model was suitable for revealing the mutual relationship of factors and predicting the response values.

\section{Mutual interactive effect of nitrogen, phosphorus and iron on lipid accumulation, biomass yield, chlorophyll, carbohydrate and protein content in Chlorella pyrenoidosa}

In orthodox one-factor time experiments, a single factor varies, kept other constant factors and the effect of interaction among the variables is ignored. The RSM systematic statistical design tool intended at exploring the relationships between design variables and responses in order to provide a better overall understanding with a minimal number of experimentations (Kirrolia et al. 2014; Myers and Montgomery 2002). The Box-Behnken design creates desirable statistical properties but most importantly with only a fraction of the trials required for a 3-level factorial so the quadratic model is suitable for data evaluation. The sensitivity of the responses of two interacting variables can be excluded by the three-dimensional graphs by holding the other variable at the central values were shown in Fig. 3a-e. The final response for biomass production, lipid accumulation, total chlorophyll, carbohydrate and protein contents in terms of coded factors is presented in Eqs. (1-5):

Model equations in terms of coded factors

$$
\begin{aligned}
\text { Biomass } \mathrm{gL}^{-1}= & +1.89+0.12 * A+0.1 * B \\
& +0.06 * C+0.040 * A * B-0.075 * A * C \\
& +0.090 * B * C-0.15 * A 2 \\
& -0.40 * B 2-0.14 * C 2
\end{aligned}
$$

$$
\begin{aligned}
\text { Lipid }(\%)= & +35.40+0.74 * A-1.86 * B \\
& +3.71 * C-0.81 * A * B+0.25 * A * C \\
& +0.67 * B * C-7.24 * A 2 \\
& -3.2 * B 2-6.69 * C 2
\end{aligned}
$$

Chlorophyll $\left(\mu \mathrm{gmL}^{-1}\right)=+20.16+0.78 * A-0.050 * B$

$$
\begin{aligned}
& -0.84 * C+0.17 * A * B \\
& -0.33 * A * C-2.34 * B * C \\
& -5.92 * A 2-4.33 * B 2-1.01 * C 2
\end{aligned}
$$

$$
\begin{aligned}
& \text { Carbohydrate }\left(\mathrm{mgmL}^{-1}\right)=+0.35+5.500 E \\
& \quad-003 * A-0.019 * B+0.03 * C \\
& \quad-6.000 E-003 * A * B+2.000 E-00 * A * C \\
& \quad+5.500 E-003 * B * C-0.071 * A 2 \\
& \quad-0.033 * B 2-0.064 * C 2
\end{aligned}
$$

$$
\begin{aligned}
& \text { Protein }\left(\mathrm{mgmL}^{-1}\right)=+0.035-6.250 E \\
& \quad-005 * A-2.650 E-003 * B \\
& \quad+2.838 E-003 * C-2.500 E-005 * A * B \\
& \quad-3.500 E-00 * A * C+1.325 E-003 * B *-7.115 E \\
& \quad-003 * A 2-1.990 E-003 * B 2-6.115 E-003 * C 2
\end{aligned}
$$

The flat bowl-shaped bottom surface of the standard error is appropriate for an RSM design with no sign of data problems were shown in Fig. 3. Statistical results showed that increase in lipid accumulation was observed with increasing the nitrogen $\left(\mathrm{NaNO}_{3}\right)$ concentration from $10 \mathrm{mg}$ to $380 \mathrm{mg} \mathrm{L}^{-1}$ in the culture medium with simultaneous increase in phosphorus and iron concentration supported biomass yield and declined with further increase in concentration of these selected variables were shown in Fig. 4a. The lipid accumulation and biomass yield of Chlorella pyrenoidosa under different initial $\mathrm{NaNO}_{3}, \mathrm{~K}_{2} \mathrm{HPO}_{4}$ and ferric ammonium citrate was shown in three-dimensional graphs (Fig. 4a) which indicated higher lipid accumulation under 


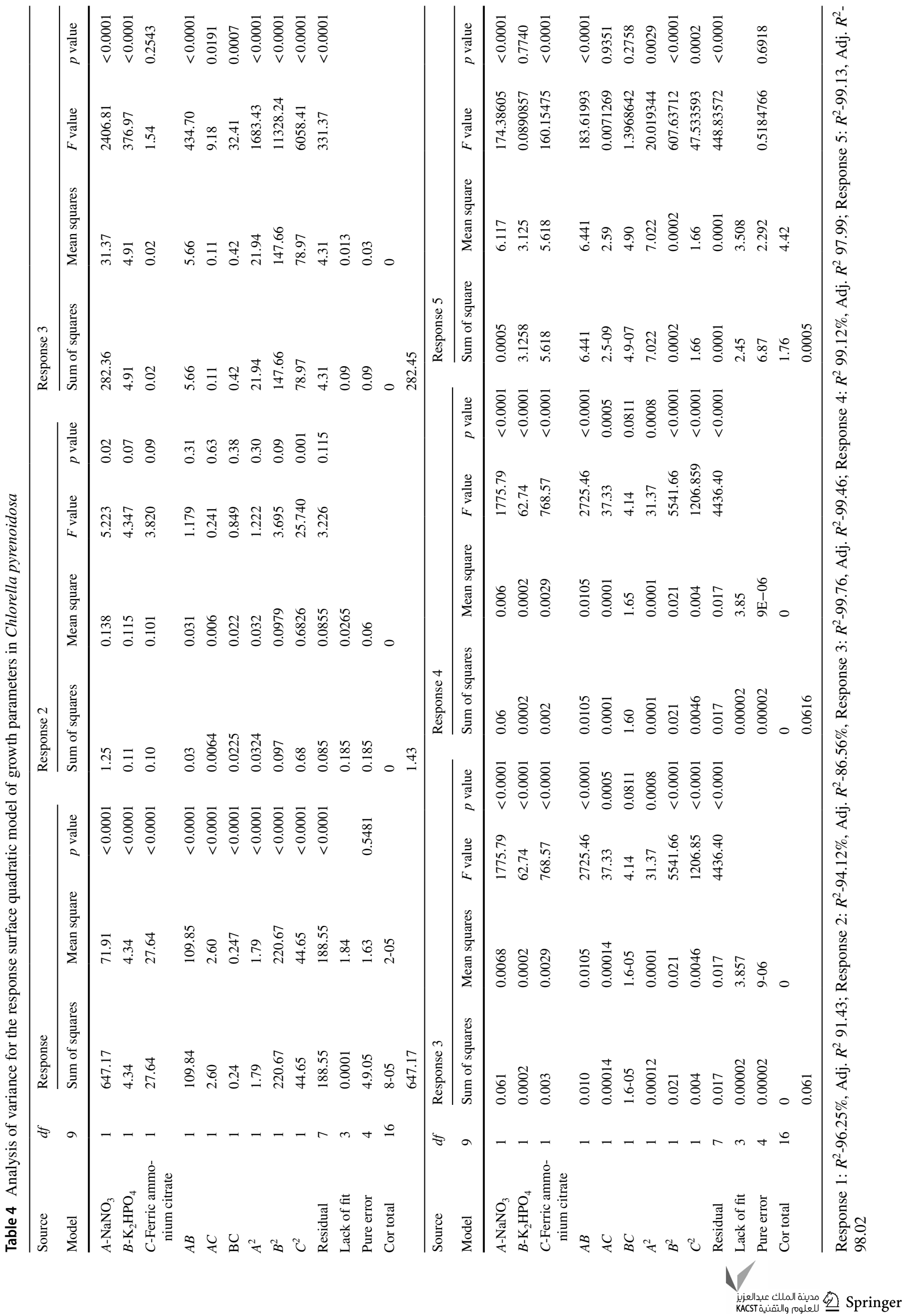




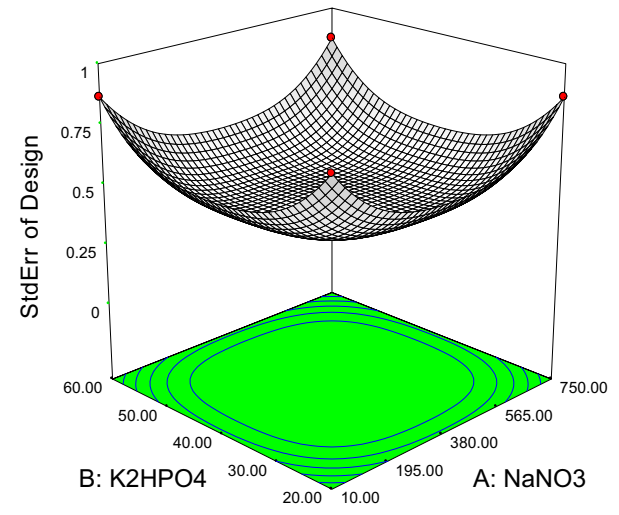

Fig. 3 Three-dimensional graph of standard error design of the model at $\mathrm{NaNO}_{3}, \mathrm{~K}_{2} \mathrm{HPO}_{4}$ and ferric ammonium conc

limited supply of nutrients of three variables (Guan et al. 2011). The higher levels of nitrate, phosphate and iron have inhibitory effects on lipid production, biomass yield, total chlorophyll, carbohydrates as well as protein concentration in experimental culture was shown in Fig. 4a-e. The highest lipid yield was obtained at $380 \mathrm{mg} \mathrm{mL}^{-1} \mathrm{NaNO}_{3}$, $40 \mathrm{mg} \mathrm{mL}{ }^{-1} \mathrm{~K}_{2} \mathrm{HPO}_{4}$ and $6 \mathrm{mg} \mathrm{mL}^{-1}$ ferric ammonium citrate, i.e. $35.4 \%$ with corresponding biomass $1.89 \mathrm{~g} \mathrm{~L}^{-1}$. $\mathrm{NaNO}_{3}$ and $\mathrm{K}_{2} \mathrm{HPO}_{4}$ were the most important variables impacting lipid production and growth, with $p$ value less than 0.0001 . With increasing phosphate, nitrate concentrations from 20 to $40 \mathrm{mg} \mathrm{L}^{-1}$ and 10 to $388 \mathrm{mg} \mathrm{L}^{-1}$, the cellular lipid content in microalgae Chlorella pyrenoidosa increased evidently, where the $p$ value was less than 0.001 . However, increased positive value $(3.71,0.67)$ of linear coefficients of phosphate and ferric ammonium citrate has much significant effects on lipid production capacity (Eq. 1). The negative values of quadratic coefficient for biomass, lipid, chlorophyll, carbohydrate and chlorophyll content $(-0.14$, $6.69,1.01,0.0064,6.11)$, respectively, infer towards an optimum value for phosphate concentration beyond which the decrease in biomass yield, lipid content, chlorophyll content, carbohydrate and protein, respectively, was observed (Eqs. 1-5). The positive linear coefficients in the model equations indicated that response values are increased with increasing the variable level and vice versa (Eqs. 1-5). Three-dimensional plots were included to the sensitivity of multiple responses of two interacting variables by holding other variables at the central values. The experimental results of BBD model are presented in Table 4 used to estimate not only main effects of variables but also their mutual interaction on growth and other variables in Chlorella pyrenoidosa. Nitrogen and phosphate are two essential macronutrients for algal growth and metabolism. Additionally, in this study simultaneous interactive effect of different factors, i.e. sodium nitrate, di-potassium hydrogen phosphate, ferric ammonium citrate in BG-11 media, was optimized. Dahmen et al. (2014) reported that Picochlorum sp. achieved the highest lipid contents under phosphate starvation condition. As reported by Ho et al. (2014), nitrogen starvation triggered the accumulation of carbohydrates in the Chlorella vulgaris.

Homogeneously spread data around either side of zero line indicated the suitability of the model for our present study. The residuals from the least squares fit also play an important role in judging the model adequacy (Myers and Montgomery 2002). The constructing a normal probability plot of the residuals, a check was made for the normality assumption. The normality assumption was satisfied as the residual plot approximated along a straight line. The general impression is that the residuals distribute randomly on the display, suggesting that the variance of the original observation is constant for all values of $Y$. All residuals plots were found to be satisfactory, thus representing the reliability of the model (Fig. 5a-e). Anand and Arumugam (2015) revealed that the 2.27-fold lipid yield was enhanced in nitrogen-depleted condition ( $226 \mathrm{mg} \mathrm{L}^{-1}$ ) when compared to nitrogen-rich condition $\left(99.33 \mathrm{mg} \mathrm{L}^{-1}\right)$. Although nitrogen limitation plays an important role in cell growth, the presence of other macronutrients (e.g. $\mathrm{Fe}, \mathrm{K}$ and $\mathrm{Mg}$ ) also affects biomass yield which might be one reason for the cell growth observed during nitrogen restriction (Converti et al. 2009; Chen et al. 2011). Nutrient availability has a substantial impact on growth and culturing of microalgae and wide effects on their lipid content and fatty acid composition (ElKassas 2013). So far, various studies have been carried out to demonstrate that the nitrogen source was the important nutrition in the medium affecting the growth and lipid accumulation ( $\mathrm{Li}$ et al. 2008). There was evidence to suggest that nitrogen deficiency could stimulate lipid accumulation (Mandal and Mallick 2009; Welter et al. 2013).

\section{Validation of the model}

The accuracy of the model was validated with experiments under the aforementioned optimal conditions. The Box-Behnken model for the growth media with varying concentration of nitrate $\left(\mathrm{NaNO}_{3}, 10-750 \mathrm{mg} \mathrm{mL}^{-1}\right)$, phosphate $\left(\mathrm{K}_{2} \mathrm{HPO}_{4}, 40-120 \mathrm{mg} \mathrm{mL}^{-1}\right)$, iron (ferric ammonium citrate 3-9 mg mL ${ }^{-1}$ ) in BG-11 media and lipid percentage (35.4 dcw\%) and biomass yield $\left(1.89 \mathrm{~g} \mathrm{~L}^{-1}\right)$ under nutrient stress condition of nitrogen, phosphorus and iron, which confirmed the validity of the predicted model. The residuals from the least squares fit also play an important role in judging the model adequacy. The normality assumption was satisfied as the residual plots approximated along a straight line (Singh et al. 2015). Relating to the enhancement of lipid accumulation in Nannochloropsis oculata, the effect of nitrogen inadequacy on lipid content in microalgal cultures has been earlier reported (Rodolfi et al. 2008; Fakhry and El Maghraby 2015; Kirrolia et al. 2014). The collective effect 
Fig. 4 Normal plots of studentized residuals verses normal percentage probability biomass. Three dimensional plot for a biomass $\left(\mathrm{g} \mathrm{L}^{-1}\right)$, b lipid accumulation (\%), $\mathbf{c}$ chlorophyll $\left(\mu \mathrm{g} \mathrm{mL} \mathrm{m}^{-1}\right), \mathbf{d}$ carbohydrate $\left(\mu \mathrm{g} \mathrm{mL}^{-1}\right)$ and e protein $\left(\mu \mathrm{g} \mathrm{mL}{ }^{-1}\right)$. A, B Response surface graphs for the interactive effect of initial concentration sodium of nitrate, di-potassium hydrogen phosphate and ferric ammonium citrate on lipid \% and biomass yield $\mathrm{g} \mathrm{L}^{-1}$ in Chlorella Pyrenoidosa. C, D Response surface graphs for the effect interactive of initial sodium nitrate concentration, di-potassium hydrogen phosphate and ferric ammonium citrate on carbohydrate and total chlorophyll content $\left(\mu \mathrm{g} \mathrm{mL}{ }^{-1}\right)$ in Chlorella pyrenoidosa. $\mathbf{E}$ Response surface graphs for interactive the effect initial concentration of Sodium nitrate, dipotassium hydrogen phosphate and ferric ammonium citrate on protein content $\mathrm{mg} \mathrm{mL}^{-1}$ in Chlorella Pyrenoidosa
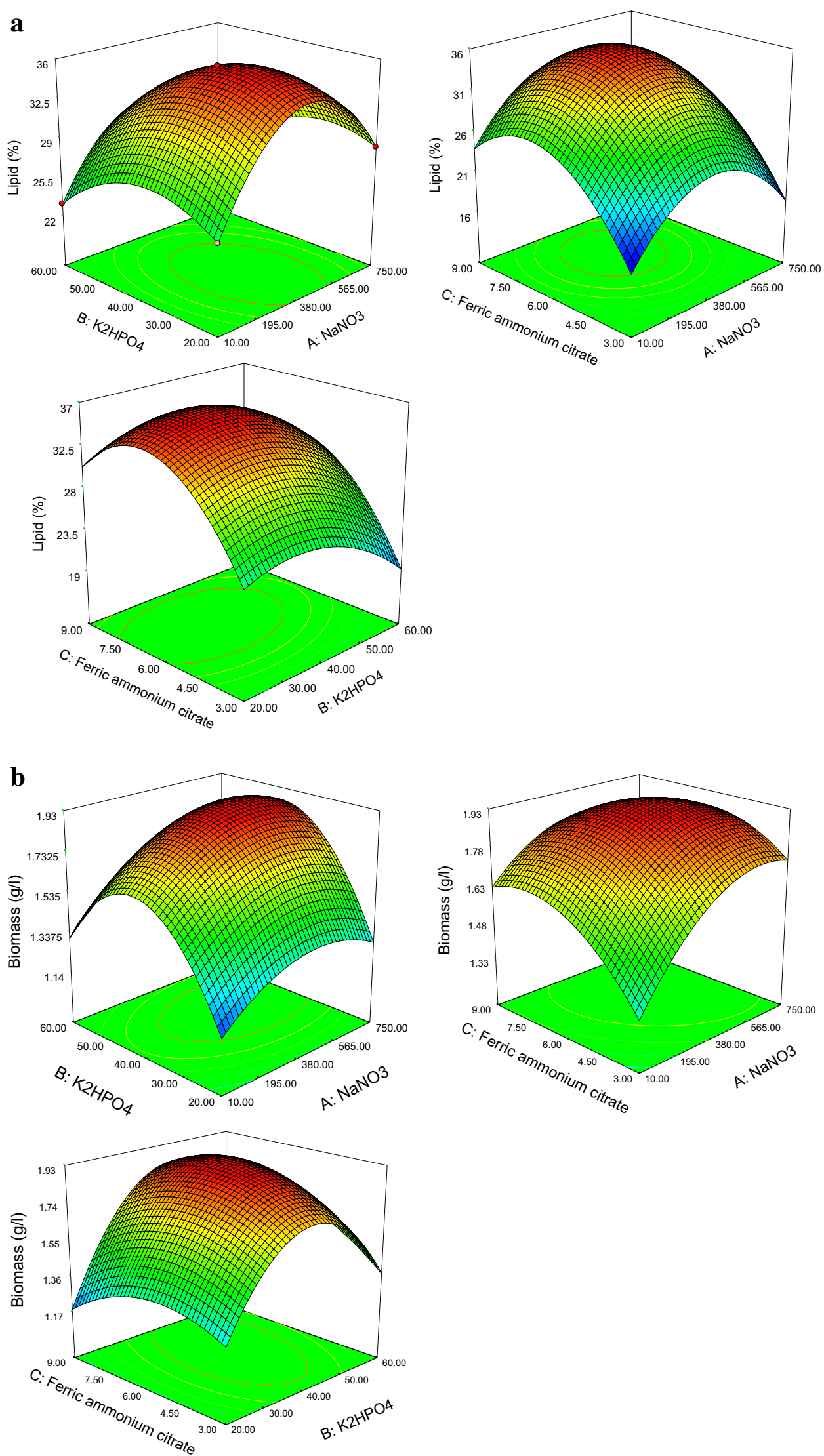
Fig. 4 (continued)

c
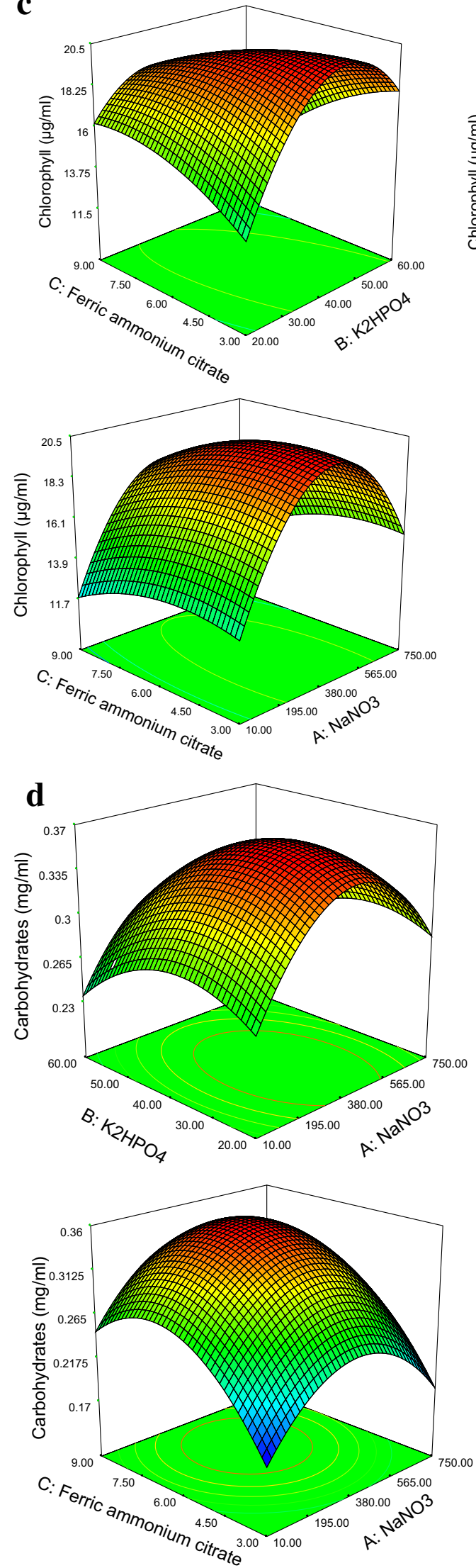
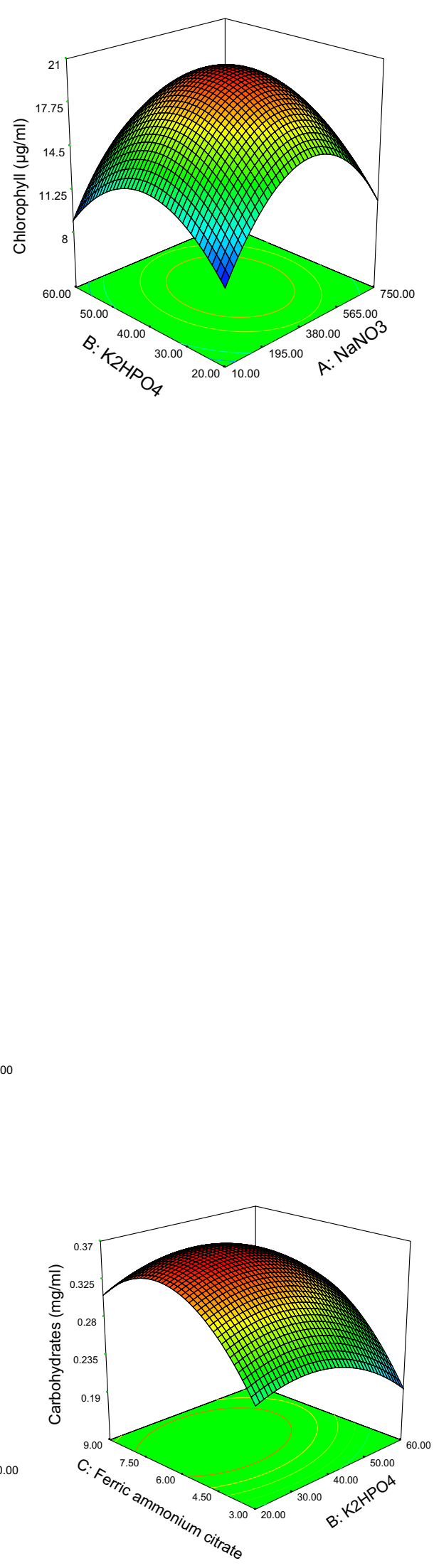
Fig. 4 (continued)
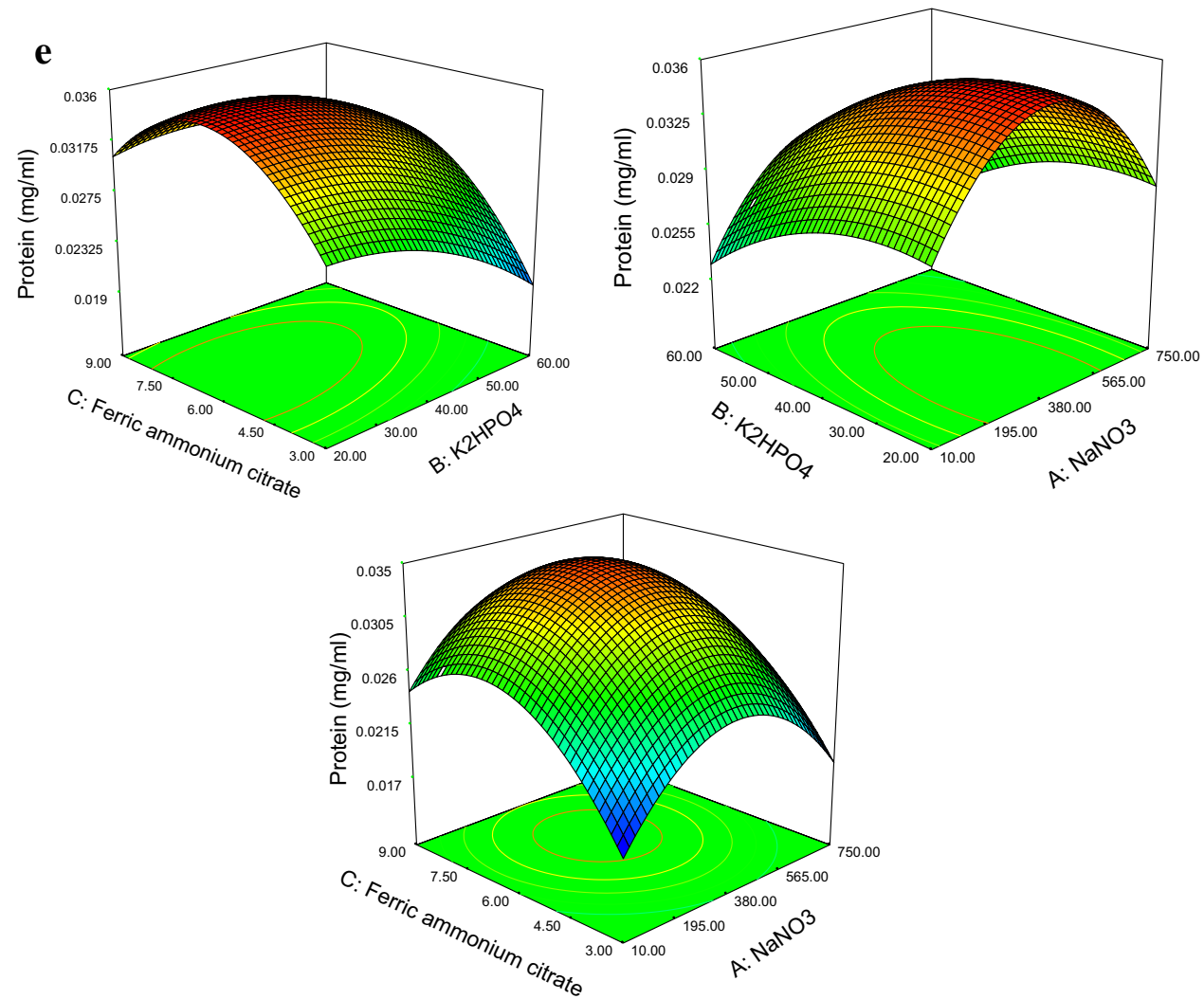

of nutrient, viz. nitrogen, phosphorous and iron stresses, on lipid productivity of selected strain was studied by response surface methodology, and the highest lipid content of $59.6 \%$ and lipid productivity of $74.07 \mathrm{mg} \mathrm{L}^{-1}$ per day was obtained in Ankistrodesmus falcatus KJ671624 (Myers and Montgomery 2002; Singh et al. 2015) as we obtained lipid percentage (35.4 dcw\%) and biomass yield $\left(1.89 \mathrm{~g} \mathrm{~L}^{-1}\right)$ under nutrient stress condition of nitrogen, phosphorus and iron.

\section{Analysis of free fatty acids (FFAs) in Chlorella pyrenoidosa}

In the present study, trans-esterification process developed by Abdo et al. (2014) was employed after optimization of reaction conditions, temperature, extraction time for preparation of FAME analysis from algal biomass and after analysis, and detection of diesel hydrocarbons. Description of typical relative percentage free fatty acids detected by GCMS in fatty acids methyl esters samples obtained through trans-esterification process was shown in Table 5 and Fig. 5. FAME composition of fresh water algal strain, Chlorella pyrenoidosa, was calculated as percentage of total esters present in the sample, determined from the peak areas. The GCMS chromatograph and free fatty acids profile of Chlorella pyrenoidosa oil individual FAME was shown in (Table 5, Fig. 5). Palmitic 16:0, palmitoleic C16:1, stearic acid C:18, oleic acid C:18:1 were detected in FAME samples. Chlorella pyrenoidosa consist of short-, medium- and long-chain diesel hydrocarbons. In Chlorella pyrenoidosa, both saturated and unsaturated fatty acids were identified. The polyunsaturated FA (4 double bond) was absent in Chlorella strains. GC-MS results revealed that the hydrocarbons such as heptacosane and 2-ethyl2 methyl tridecanol were detected among the hydrocarbons produced by Chlorella pyrenoidosa. The saturated fatty acids were identified mainly as palmitic acid methyl ester (C16:0, 33.91\%) by trans-methylation trans-esterification process. As per previous study, short-chain hydrocarbons ( $<\mathrm{C} 20)$ were commonly present in Chlorella pyrenoidosa than compared to long-chain hydrocarbons (> C19) (Matsumoto et al. 2010). As per one study, Chlorella sp. possessed maximum linolenic acid (C18:3) (14.20\%). On the other hand, the unsaturated fatty acids have been detected as palmitoleic methyl ester (C16:1, 12.05\%), 18:1 oleic acid methyl esters, (22.72\%), C18:2 (9.26\%) linoleic acid have been detected in direct trans-methylation process (Abdo et al. 2014). Similar fatty acids profile has been detected in Chlorella sp. and Scenedesmus sp. by direct trans-esterification process (Kirrolia 2015). Hence, the above results stated that Chlorella pyrenoidosa possessed a approving fatty acids profile that can be successfully utilized for biodiesel production. 
Fig. 4 (continued)
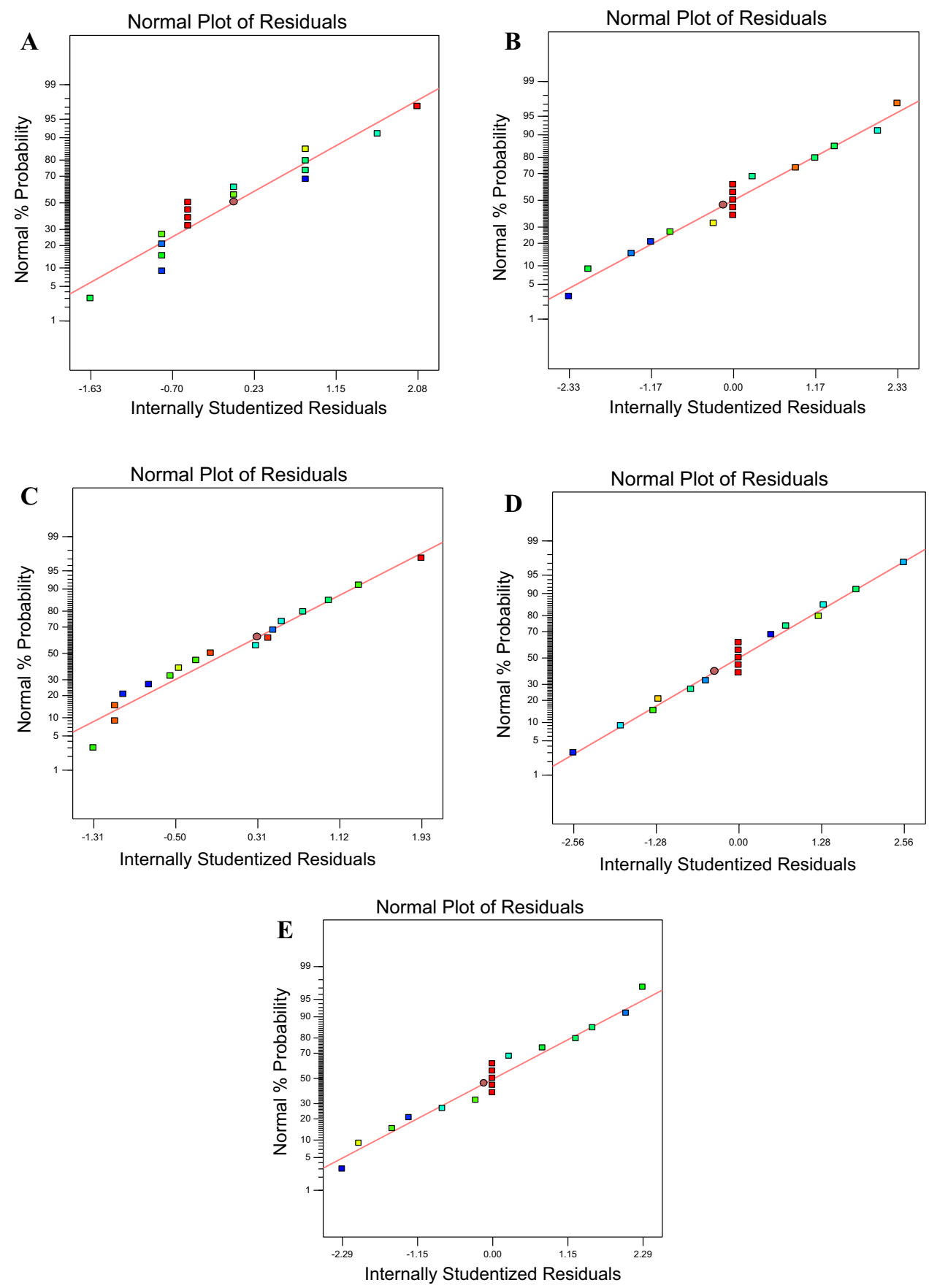

\section{Conclusion}

Microalgal biodiesel appeared to be the most promising renewable third-generational biofuel. Chlorella microalgae is considered as a promising for industrial-scale biodiesel production as it possessed elevated biomass, rapid growth lipid content and fatty acid productivity. In conventional one-factor time experiments, a single factor varies, keeping other factors constant, and the effect of interaction among the variables is disregarded. The RSM is a logical statistical design methodology aimed at exploring the interactions between design variables and responses in order to provide a better overall understanding with less number of experiments for optimum biomass and cellular lipid content. Lipid content, biomass, carbohydrate, chlorophyll, protein and biomass produced were studied under varied concentration of nutrients in BG11 media, nitrate $\left(\mathrm{NaNO}_{3}\right.$, $\left.10-750 \mathrm{mg} \mathrm{mL}^{-1}\right)$, phosphate $\left(\mathrm{K}_{2} \mathrm{HPO}_{4}, 40-120 \mathrm{mg} \mathrm{mL}^{-1}\right)$, iron (ferric ammonium citrate $3-9 \mathrm{mg} \mathrm{mL}^{-1}$ ) with an aim to establish the actual potential of Chlorella pyrenoidosa under phototrophic nutrient stress conditions; we obtained lipid percentage (35.4 dcw\%) and biomass yield $\left(1.89 \mathrm{~g} \mathrm{~L}^{-1}\right)$ 
$\mathbf{a}$

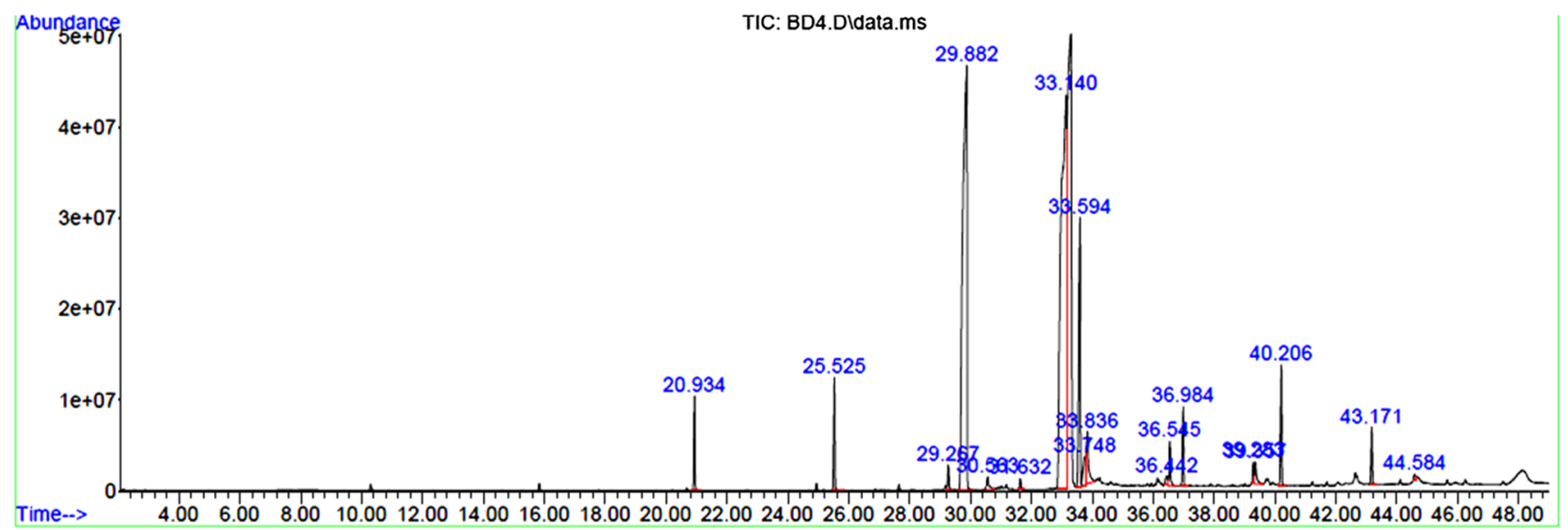

b $_{\text {Hit 1: cis-10-Heptadecenoic acid, methyl ester }}$

1843402; MF: 944; RMF: 946; Prob 70 4\%; Lb: mainlib; ID: 18892.

100

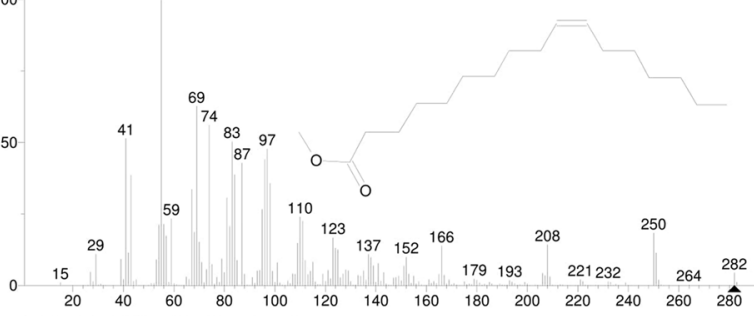

d

Hit 1 : Pentadecanoic acid, methyl ester

C16H3202; MF: 951; RMF: 952; Prob 80.1\%; CAS: 7132-64-1; Lib: mainlib; ID: 40710

100

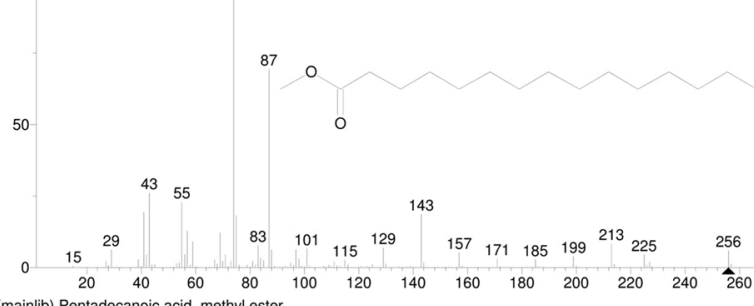
(mainlib) Pentadecanoic acid, methyl ester
C Hit 1: Hexadecanoic acid, ethyl ester
C18H3602; MF: 914; RMF: 914; Prob 86

Hit 1: Hexadecanoic acid, ethyl ester
C18H3602; MF: 914; RMF: 914; Prob 86.4\%; CAS: 628-97-7; Lib: mainlib; ID: 52733 .

100

88
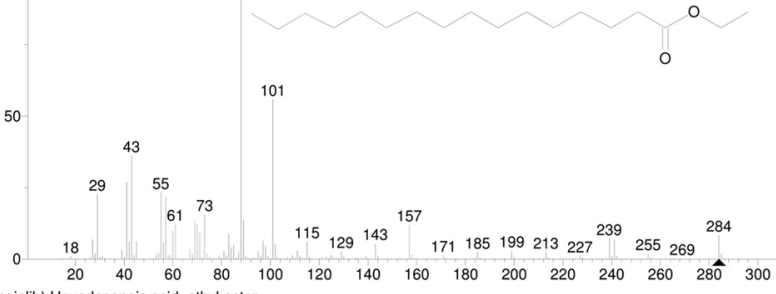
(mainlib) Hexadecanoic acid, ethyl ester Hit 1: 9,12-Octadecadienoic acid (Z,Z)-, methyl ester
C19H3402; MF: 961; RMF: 962; Prob 43.5\%; CAS: 112-63-0; Lib: mainlib; ID: 30167

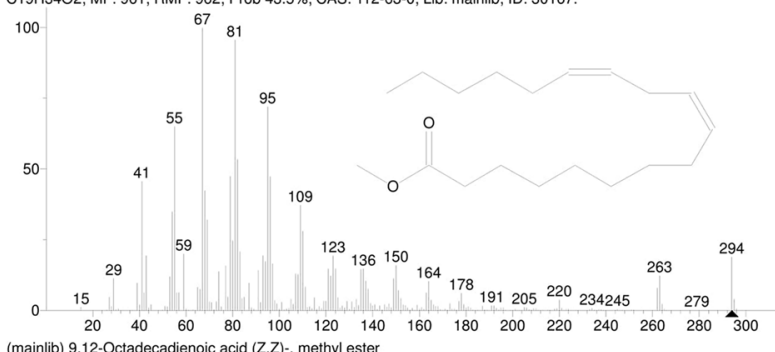

Fig. 5 GCMS mass spectra of Chlorella pyrenoidosa $\mathbf{a}$ palmitic acid, $\mathbf{b}$ stearic acid, $\mathbf{c}$ oleic acid and $\mathbf{d}$ linoleic acid

under nutrient stress condition of nitrogen, phosphorus and iron, which confirmed the validity of the predicted model. GCMS study revealed that palmitic 16:0, palmitoleic C16:1, stearic acid C:18, oleic acid C:18:1 were detected in FAME samples of Chlorella pyrenoidosa which makes it potential biodiesel-producing strain. Further, large-scale production of microalgal biodiesel at industrial applications prerequisites to resolve several environmental, economically and technological issues and microalgal oil productivity per acre can be improved by acquainting synthetic biology techniques, as well as refining the light source systems (Arudchelvam and Nirmalakhandan 2013). 
Table 5 Analysis of free fatty acids (FFAs) of Chlorella pyrenoidosa

\begin{tabular}{|c|c|c|c|c|c|}
\hline S. no & Common name & IUPAC name & Abbreviation & Molecular formula & $\begin{array}{l}\text { Free fatty acids detected in Chlorella } \\
\text { pyrenoidosa oil samples (FAME) (\%) }\end{array}$ \\
\hline 1. & Caproic acid & Hexaonic acid & C6:0 & $\mathrm{C}_{6} \mathrm{H}_{12} \mathrm{O}_{2}$ & ND \\
\hline 2. & Caprylic acids & Octanoic acid & $\mathrm{C} 8: 0$ & $\mathrm{C}_{8} \mathrm{H}_{16} \mathrm{O}_{2}$ & ND \\
\hline 3. & Undecanoic acid & Undecanoic acid & $\mathrm{C} 11: 0$ & $\mathrm{C}_{11} \mathrm{H}_{22} \mathrm{O}_{2}$ & 5.21 \\
\hline 4. & Lauric acid & Dodecanoic acid & $\mathrm{C} 12: 0$ & $\mathrm{C}_{12} \mathrm{H}_{24} \mathrm{O}_{2}$ & 1.51 \\
\hline 5. & Lauric acid & Dodecanoic acid & $\mathrm{C} 12: 1$ & $\mathrm{C}_{13} \mathrm{H}_{26} \mathrm{O}_{2}$ & 0.12 \\
\hline 6. & Myristic acid & Tetradecanoic acid & C14:0 & $\mathrm{C}_{14} \mathrm{H}_{28} \mathrm{O}_{2}$ & 0.31 \\
\hline 7. & Pentadecanoic acid & Pentadecanoic acid & C15:0 & $\mathrm{C}_{15} \mathrm{H}_{30} \mathrm{O}_{2}$ & 1.65 \\
\hline 8. & Pentadecenoic acid & Cis-10-heptadecenoic acid & $\mathrm{C} 15: 1$ & $\mathrm{C}_{15} \mathrm{H}_{28} \mathrm{O}_{2}$ & ND \\
\hline 9. & Palmitic acids & Hexadecanoic acid & $\mathrm{C} 16: 0$ & $\mathrm{C}_{16} \mathrm{H}_{32} \mathrm{O}_{2}$ & 33.912 \\
\hline 10. & Palmitoleic acids & Cis-9-Cis-10-heptadecenoic acid & C16:1 & $\mathrm{C}_{16} \mathrm{H}_{30} \mathrm{O}_{2}$ & 12.05 \\
\hline 11. & Margaric acids & Heptadeconic acids & C17:0 & $\mathrm{C}_{17} \mathrm{H}_{34} \mathrm{O}_{2}$ & 0.53 \\
\hline 12. & Cis-10-heptadecenoic acid & Cis-10-heptadecenoic acid & $\mathrm{C} 17: 1$ & $\mathrm{C}_{17} \mathrm{H}_{32} \mathrm{O}_{2}$ & ND \\
\hline 13. & Stearic acid & Octadecanoic acid & C18:0 & $\mathrm{C}_{18} \mathrm{H}_{36} \mathrm{O}_{2}$ & 1.782 \\
\hline 14. & Oleic acid & Cis-9-octadecanoic acid & C18:1 & $\mathrm{C}_{18} \mathrm{H}_{34} \mathrm{O}_{2}$ & 22.72 \\
\hline 15. & Linoleic acid & Cis-9,12,octadecadienoic acid & C18:2 & $\mathrm{C}_{18} \mathrm{H}_{32} \mathrm{O}_{2}$ & 9.286 \\
\hline 16. & Linolenic acid & Cis-9,12,15-octatetradecoic acids & $\mathrm{C} 18: 3$ & $\mathrm{C}_{18} \mathrm{H}_{30} \mathrm{O}_{2}$ & 11.58 \\
\hline 17. & Nonadecanoic acid & Nonadecyclic acid & C19:0 & $\mathrm{C}_{19} \mathrm{H}_{88} \mathrm{O}_{2}$ & 0.585 \\
\hline 18. & Arachidic acid & Eicosanoic acid & C20:0 & $\mathrm{C}_{20} \mathrm{H}_{40} \mathrm{O}_{2}$ & 7.395 \\
\hline 19. & Behenic acid & Docosenoic acid & $\mathrm{C} 22: 0$ & $\mathrm{C}_{22} \mathrm{H}_{44} \mathrm{O}_{2}$ & ND \\
\hline 20. & Erucic acid & Cis-13-docosenoic acid & $\mathrm{C} 22: 1$ & $\mathrm{C}_{22} \mathrm{H}_{42} \mathrm{O}_{2}$ & ND \\
\hline \multirow[t]{4}{*}{21.} & Heptacosylic acid & Heptacosanoic acid & C27:0 & $\mathrm{C}_{27} \mathrm{H}_{56} \mathrm{O}_{2}$ & 0.166 \\
\hline & & & & SFAs $\%$ & 44.37 \\
\hline & & & & MUFA $\%$ & 34.77 \\
\hline & & & & PUFA\% & 20.86 \\
\hline
\end{tabular}

Relative percentage of free acids detected by GCMS

SFA Saturated fatty acids, MUFA monounsaturated fatty acids, PUFA polyunsaturated fatty acids

Acknowledgements The authors are highly thankful to Department of Environmental Science and Engineering, Guru Jambheshwar university of Science and Technology, Hisar (Haryana), for providing required facilities during the research work. The authors also wish to thank the University Grant Commission (MANF, SRF) for the financial support.

Open Access This article is distributed under the terms of the Creative Commons Attribution 4.0 International License (http://creativeco mmons.org/licenses/by/4.0/), which permits unrestricted use, distribution, and reproduction in any medium, provided you give appropriate credit to the original author(s) and the source, provide a link to the Creative Commons license, and indicate if changes were made.

\section{References}

Abdo SM, Ahmed E, El-Enin SA, El Din RS, Ali GEDG (2014) Qualitative and quantitative determination of lipid content in microalgae for biofuel production. J Algal Biomass Utln 5(3):23-28

Anand J, Arumugam M (2015) Enhanced lipid accumulation and biomass yield of Scenedesmus quadricauda under nitrogen starved condition. Bioresour Technol 188:190-194
Arudchelvam Y, Nirmalakhandan N (2013) Energetic optimization of microalgal cultivation in photobioreactors for biodiesel production. Renew Energy 56:77-84

Bajwa K, Bishnoi NR (2016) Effect of glucose supplementation and mixotrophic effects of glycerol and glucose on the production of biomass, lipid yield and different physiological, biochemical attributes of Chlorella pyrenoidosa. J Algal Biomass Utiln 7(1):93-103

Bligh EG, Dyer WJ (1959) A rapid method of total lipid extraction and purification. Can J Biochem Physiol 37(8):911-917

Blinová L, Bartošová A, Gerulová K (2015) Cultivation of microalgae (Chlorella vulgaris) for biodiesel production. Res Pap Fac Mater Sci Technol Slovak Univ Technol 23(36):87-95

Box GEP, Behnken DW (1960) Some new three level designs for the study of quantitative variables. Technometrics 2:455-475

Cheirsilp B, Torpee S (2012) Enhanced growth and lipid production of microalgae under mixotrophic culture condition: effect of light intensity, glucose concentration and fed-batch cultivation. Bioresour Technol 110:510-516

Chelladurai C, Perumalsamy M (2017) Statistical study on the growth of Chlorella pyrenoidosa using the response surface methodology. Curr Biochem Eng 4(1):43-59

Chen W, Sommerfeld M, Hu Q (2011) Microwave-assisted Nile red method for in vivo quantification of neutral lipids in microalgae. Bioresour Technol 102(1):135-141 
Chisti Y (2008) Biodiesel from microalgae beats bioethanol. Trends Biotechnol 26(3):126-131

Chuah LF, Yusup S, Aziz ARA, Klemeš JJ, Bokhari A, Abdullah MZ (2016) Influence of fatty acids content in non-edible oil for biodiesel properties. Clean Technol Environ Policy 18(2):473-482

Converti A, Casazza AA, Ortiz EY, Perego P, Del Borghi M (2009) Effect of temperature and nitrogen concentration on the growth and lipid content of Nannochloropsis oculata and Chlorella vulgaris for biodiesel production. Chem Eng Process Process Intensif 48(6):1146-1151

Courchesne NMD, Parisien A, Wang B, Lan CQ (2009) Enhancement of lipid production using biochemical, genetic and transcription factor engineering approaches. J Biotechnol 141(1):31-41

Dahmen I, Chtourou H, Jebali A, Daassi D, Karray F, Hassairi I, Dhouib A (2014) Optimization of the critical medium components for better growth of Picochlorum sp. and the role of stressful environments for higher lipid production. J Sci Food Agric 94(8):1628-1638

Dubois M, Gilles KA, Hamilton JK, Rebers PAT, Smith F (1956) Colorimetric method for determination of sugars and related substances. Anal Chem 28(3):350-356

El-Kassas HY (2013) Growth and fatty acid profile of the marine microalga Picochlorum Sp. grown under nutrient stress conditions. Egypt J Aquat Res 39(4):233-239

Fadhil AB, Aziz AM, Al-Tamer MH (2016) Biodiesel production from Silybum marianum $L$. seed oil with high FFA content using sulfonated carbon catalyst for esterification and base catalyst for transesterification. Energy Convers Manag 108:255-265

Fakhry EM, El Maghraby DM (2015) Lipid accumulation in response to nitrogen limitation and variation of temperature in Nannochloropsis salina. Bot Stud 56(1):1-6

Gao Y, Yang M, Wang C (2013) Nutrient deprivation enhances lipid content in marine microalgae. Bioresour Technol 147:484-491

Guan W, Zhao H, Lu X et al (2011) Quantitative analysis of fattyacid-based biofuels produced by wild-type and genetically engineered cyanobacteria by gas chromatography-mass spectrometry. J Chromatogr A 1218:8289-8293

Harun R, Singh M, Forde GM, Danquah MK (2010) Bioprocess engineering of microalgae to produce a variety of consumer products. Renew Sustain Energy Rev 14(3):1037-1047

Ho SH, Chan MC, Liu CC, Chen CY, Lee WL, Lee DJ, Chang JS (2014) Enhancing lutein productivity of an indigenous microalga Scenedesmus obliquus FSP-3 using light-related strategies. Bioresour Technol 152:275-282

Hsieh CH, Wu WT (2009) Cultivation of microalgae for oil production with a cultivation strategy of urea limitation. Bioresour Technol 100(17):3921-3926

Illman AM, Scragg AH, Shales SW (2000) Increase in Chlorella strains calorific values when grown in low nitrogen medium. Enzym Microb Technol 27(8):631-635

Kiran B, Kumar R, Deshmukh D (2014) Perspectives of microalgal biofuels as a renewable source of energy. Energy Convers Manag 88:1228-1244

Kirrolia A (2015) A study on biodiesel production from microalgae. Ph.D. thesis, Guru Jambheshwar University of Science \& Technology, Hisar (Haryana)

Kirrolia A, Bishnoi NR, Singh R (2014) Response surface methodology as a decision-making tool for optimization of culture conditions of green microalgae Chlorella spp. for biodiesel production. Ann Microbiol 64(3):1133-1147

Kumar N, Chauhan SR (2013) Performance and emission characteristics of biodiesel from different origins: a review. Renew Sustain Energy Rev 21:633-658

Li Y, Horsman M, Wang B, Wu N, Lan CQ (2008) Effects of nitrogen sources on cell growth and lipid accumulation of green alga Neochloris oleoabundans. Appl Microbiol Biotechnol 81(4):629-636

Lowry OH, Rosebrough NJ, Farr AL, Randall RJ (1951) Protein measurement with the Folin phenol reagent. J Biol Chem 193(1):265-275

Ma F, Hanna MA (1999) Biodiesel production: a review. Bioresour Technol 70(1):1-15

Mackinney G (1941) Absorption of light by chlorophyll solutions. J Biol Chem 140(2):315-322

Mandal S, Mallick N (2009) Microalga Scenedesmus obliquus as a potential source for biodiesel production. Appl Microbiol Biotechnol 84(2):281-291

Masurkar AA, Vakil BV (2015) Optimization of process variables for bacterial PUFA production by OFAT method. Int J Curr Microbiol Appl Sci 4(7):160-181

Mata TM, Martins AA, Caetano NS (2010) Microalgae for biodiesel production and other applications: a review. Renew Sustain Energy Rev 14(1):217-232

Matsumoto M, Sugiyama H, Maeda Y, Sato R, Tanaka T, Matsunaga T (2010) Marine diatom, Navicula sp. strain JPCC DA0580 and marine green alga, Chlorella sp. strain NKG400014 as potential sources for biodiesel production. Appl Biochem Biotechnol 161(1-8):483-490

Miao X, Xu H, Wu Q (2006) High quality biodiesel production from a microalga Chlorella protothecoides by heterotrophic growth in fermenters. J Biotechnol 126(4):499-507

Molina Grima E, Fernandez F, Garcia Camacho F et al (1999) Photobioreactors: light regime, mass transfer, and scale up. J Biotechnol 70:231-247

Myers RH, Montgomery DC (2002) Response surface methodology: process and product optimization using designed experiments, 2nd edn. Wiley, New York

Noureddini H, Gao X, Philkana RS (2005) Immobilized Pseudomonas cepacia lipase for biodiesel fuel production from soybean oil. Bioresour Technol 96(7):769-777

Quehenberger O, Armando AM, Dennis EA (2011) High sensitivity quantitative lipidomics analysis of fatty acids in biological samples by gas chromatography-mass spectrometry. Biochim Biophys Acta (BBA) Mol Cell Biol Lipids 1811(11):648-656

Radakovits R, Jinkerson RE, Darzins A, Posewitz MC (2010) Genetic engineering of algae for enhanced biofuel production. Eukaryot Cell 9(4):486-501

Ren HY, Liu BF, Ma C, Zhao L, Ren NQ (2013) A new lipid-rich microalga Scenedesmus sp. strain R-16 isolated using Nile red staining: effects of carbon and nitrogen sources and initial $\mathrm{pH}$ on the biomass and lipid production. Biotechnol Biofuels 1(1):6

Renita A, Joshua AD (2011) Multifaceted applications of marine macro algae Sargassum myriocystum. J Pharm Res 4(11):3871-3872

Rodolfi L, Chini Zittelli G, Bassi N, Padovani G, Biondi N, Bonini G, Tredici MR (2008) Microalgae for oil: strain selection, induction of lipid synthesis and outdoor mass cultivation in a low-cost photobioreactor. Biotechnol Bioeng 102:100-112

Rogers SO, Bendich AJ (1994) Extraction of total cellular DNA from plant, algae and fungi. Plant Mol Biol Man D1:1-8

Shahare VV, Kumar B, Singh P (2017) Biofuels for sustainable development: a global perspective. In: Singh R, Kumar S (eds) Green technologies and environmental sustainability. Springer, Cham, pp 67-89

Sharma KK, Schuhmann H, Schenk PM (2012) High lipid induction in microalgae for biodiesel production. Energies 5(5):1532-1553

Sharma AK, Sahoo PK, Singhal S (2015) Screening and optimization of culture media for Chlorella sp. as a raw material for biodiesel production. Int J Pharma Bio Sci 6(3):251-262

Show PL, Tang MS, Nagarajan D, Ling TC, Ooi CW, Chang JS (2017) A holistic approach to managing microalgae for biofuel applications. Int J Mol Sci 18(1):215

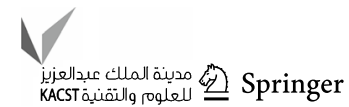


Silambarasan TS, Bajwa K, Dhandapani R (2017) Optimization and mass culture of Acutodesmus obliquus RDS01 under open phototrophic pond cultivation for enhancing biodiesel production. Biofuels 8(2):243-252

Singh SP, Singh P (2015) Effect of temperature and light on the growth of algae species: a review. Renew Sustain Energy Rev 50:431-444

Singh P, Guldhe A, Kumari S, Rawat I, Bux F (2015) Investigation of combined effect of nitrogen, phosphorus and iron on lipid productivity of microalgae Ankistrodesmus falcatus KJ671624 using response surface methodology. Biochem Eng J 94:22-29

Su WT, Chen WJ, Lin YF (2009) Optimizing emulsan production of A. venetianus RAG-1 using response surface methodology. Appl Microbiol Biotechnol 84(2):271-279

Suganya T, Renganathan S (2012) Optimization and kinetic studies on algal oil extraction from marine macroalgae Ulva lactuca. Bioresour Technol 107:319-326

Tokcaer Z, Bayraktar E, Mehmetoğlu Ü, Özcengiz G, Alaeddinoğlu NG (2006) Response surface optimization of antidipteran deltaendotoxin production by Bacillus thuringiensis subsp. israelensis HD 500. Process Biochem 41(2):350-355

Wang Y, Ou S, Liu P, Zhang Z (2007) Preparation of biodiesel from waste cooking oil via two-step catalyzed process. Energy Convers Manag 48(1):184-188

Wang L, Li Y, Chen P, Min M, Chen Y, Zhu J, Ruan RR (2010) Anaerobic digested dairy manure as a nutrient supplement for cultivation of oil-rich green microalgae Chlorella sp. Bioresour Technol 101(8):2623-2628

Welter C, Schwenk J, Kanani B, Van Blargan J, Belovich JM (2013) Minimal medium for optimal growth and lipid production of the microalgae Scenedesmus dimorphus. Environ Prog Sustain Energy 32(4):937-945

Yount R (2006) Advanced statistical procedures, research design and statistical analysis in Christian Ministry. Southwestern Baptist Theological Seminary, Fort Worth

Yu H, Jia S, Dai Y (2009) Growth characteristics of the cyanobacterium Nostoc flagelliforme in photoautotrophic, mixotrophic and heterotrophic cultivation. J Appl Phycol 21(1):127-133

Yu N, Dieu LTJ, Harvey S, Lee DY (2015) Optimization of process configuration and strain selection for microalgae-based biodiesel production. Bioresour Technol 193:25-34

Zhang Y, Dube MA, McLean D, Kates M (2003) Biodiesel production from waste cooking oil: 1. Process design and technological assessment. Biores Technol 89(1):1-16

Publisher's Note Springer Nature remains neutral with regard to jurisdictional claims in published maps and institutional affiliations. 